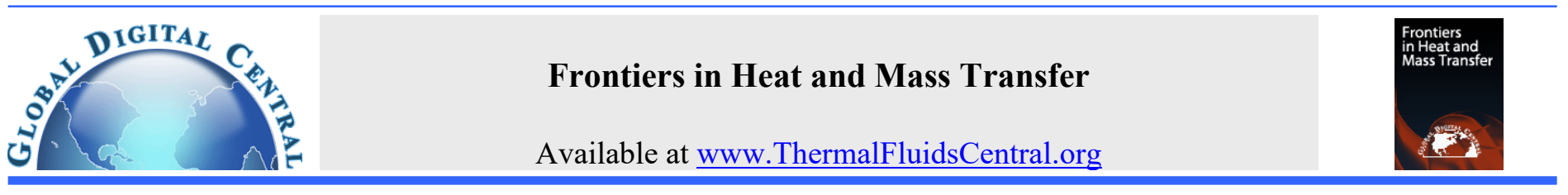

\title{
COMPARISON OF CFD AND EMPIRICAL MODELS FOR PREDICTING WALL TEMPERATURE AT SUPERCRITICAL CONDITIONS OF WATER
}

\author{
S. Anand ${ }^{\mathrm{a}}$ S. Suresh ${ }^{\mathrm{a}}$, R. Dhanuskodi ${ }^{\mathrm{b}}$, D. Santhosh Kumar ${ }^{\mathrm{b},{ }^{*}}$ \\ ${ }^{a}$ Department of Mechanical Engineering, National Institute of Technology, Trichy, Tamilnadu, 620015, India \\ ${ }^{b}$ Research \& Development Department, Bharath Heavy Elecricals, Ltd., Trichy, Tamilnadu. 620014, India
}

\begin{abstract}
The present work investigates the wall temperature prediction at supercritical pressure of water by CFD and compares the prediction of CFD and that of 11 empirical correlations available in literature. Supercritical-water heat transfer experimental data, covering a mass flux range of $400-1500$ $\mathrm{kg} / \mathrm{m}^{2} \mathrm{~s}$, heat flux range of $150-1000 \mathrm{~kW} / \mathrm{m}^{2}$, at pressure $241 \mathrm{bar}$ and diameter $10 \mathrm{~mm}$ tube, were obtained from literature. CFD simulations have been carried out for those operating conditions and compared with experimental data. Around 362 experimental wall temperature data of both heat transfer enhancement and heat transfer deterioration region have been taken for comparison. A visual Basic program has also been developed to predict wall temperature for the selected empirical correlations and compared with those of 362 experimental data. Ranking based on the deviation with experimental data is also listed.
\end{abstract}

Keywords: SST-kw model, heat transfer enhancement, heat transfer deterioration, supercritical water

\section{INTRODUCTION}

The Advanced Ultra Supercritical Boilers will be the next generation of boilers because it possesses various advantages like relatively low energy cost, low pollutant emission and high efficiency. The Advanced Ultra Supercritical Boilers are aimed to operate at a pressure and temperature of $300 \mathrm{bar}$ and $700^{\circ} \mathrm{C}$ respectively with a higher thermal efficiency up to $46 \%$. As the water walls operate at conditions above the critical point of water, which is 221 bar and $374^{\circ} \mathrm{C}$, the fluid will remain as a single phase. Thus no departure from nucleate boiling or dry-out can occur. However in the vicinity of this critical point, strong variations of water properties combined with a high heat flux or low mass flux can lead to heat transfer deterioration (HTD), which consequently causes a severe increase of wall temperature (Cheng et.al., 2003). Thus, the study of heat transfer behavior at pseudocritical region is extremely important. It has been found that the fluid temperature and pressure in the evaporator region varies between $342^{\circ} \mathrm{C} \& 440^{\circ} \mathrm{C}$ and $270 \& 290$ bar respectively at Boiler Maximum Continuous Rating condition. The pseudocritical temperature at 270 and $290 \mathrm{bar}$ is found to be $392^{\circ} \mathrm{C}(2177.39 \mathrm{~kJ} / \mathrm{kg})$ and $399^{\circ} \mathrm{C}(2204.21$ $\mathrm{kJ} / \mathrm{kg}$ ). This indicates that somewhere in the evaporator region the fluid crosses the pseudocritical temperature. Therefore, it is indeed necessary to study the heat transfer behavior at pseudocritical temperature at the desired pressure range and determine the inner wall temperature.

Various experimental investigations have been performed at supercritical conditions with water flowing upward in circular pipes under intense electrical heating (Bishop et al., 1964; Yamagata et al., 1972; Jackson and Hall, 1979; Zhu et al., 2009) and published empirical correlations applicable for predicting the heat transfer at supercritical conditions of water. Each correlation is applicable for the specified range of operating parameters. These correlations are used for determining the inner wall temperature. Several established dimensionless correlations for heat transfer of supercritical water namely, Dittus-Boelter, 1930; McAdams, 1942, Bishop et al., 1964; Shitsman, 1968; Ornatsky et al., 1971; Yamagata et al., 1972; Jackson and Hall, 1979; Watts and Chou, 1982; Griem, 1996; Zhu et al., 2009; Mokry et al., 2011 etc., are available in the literature to predict the wall temperature. Nevertheless, the comparisons of experimental data and correlations still show considerable disagreement at the regimes of the heat transfer deterioration. This is because the derivation of all the existing correlations was based on their own experimental dataset. This is one of the main drawbacks of empirical correlations. Numerical studies indeed become necessary in order to obtain more insight into the heat transfer behavior in supercritical fluids.

The accuracy of numerical simulations of heat transfer in supercritical may depend on the choice of turbulence models. A number of investigations about the application of turbulence models in the numerical simulation of flow and heat transfer for supercritical water have been carried out. But, standard wall functions of the turbulence models are not capable to predict heat transfer deterioration. Jaromin and Anglart (2013) found that SST k- $\omega$ model is capable to predict heat transfer deterioration close to the experimental results. Wen and $\mathrm{Gu}$ (2011) also validated few turbulent models and found that SST k- $\omega$ is more accurate than other models. Zhi et al. (2016) used SST k- $\omega$ model for predicting convective heat transfer to hydro carbon fuel at supercritical pressure and assured that it performs well compared to all other turbulence models under supercritical pressure. He also employed the SST k- $\omega$ model in his analysis and validated with experimental results and showed that SST k- $\omega$ model is capable for predicting the heat transfer enhancement and heat transfer deterioration. In the present work, simulations were carried out using various turbulence models available in Ansys-Fluent to gain confidence.

The purpose of the present work is to numerically simulate the experimental conditions consisting of 362 data points available in literature for a range of parameters such as heat flux, mass flux, bulk fluid enthalpy, pressure, and tube diameter and compare the wall temperature predicted by CFD and 11 empirical correlations with the experimental data. 


\subsection{Definitions of terms and properties of Supercritical water}

Critical point is the point where the distinction between the liquid and gas (or vapor) phases disappears, i.e., both phases have the same temperature, pressure and volume (Fig. 1, Pioro and Duffey, 2005). The critical point is characterized by the phase state parameters $T_{c r}, P_{c r}$ and $V_{\mathrm{cr}}$, which have unique values for each pure substance.

Pseudocritical point (characterized with $P_{p c}$ and $T_{p c}$ ) is a point at a pressure above the critical pressure and at a temperature $\left(T_{p c}>\right.$ $T_{c r}$ ) corresponding to the maximum value of the specific heat for this particular pressure.

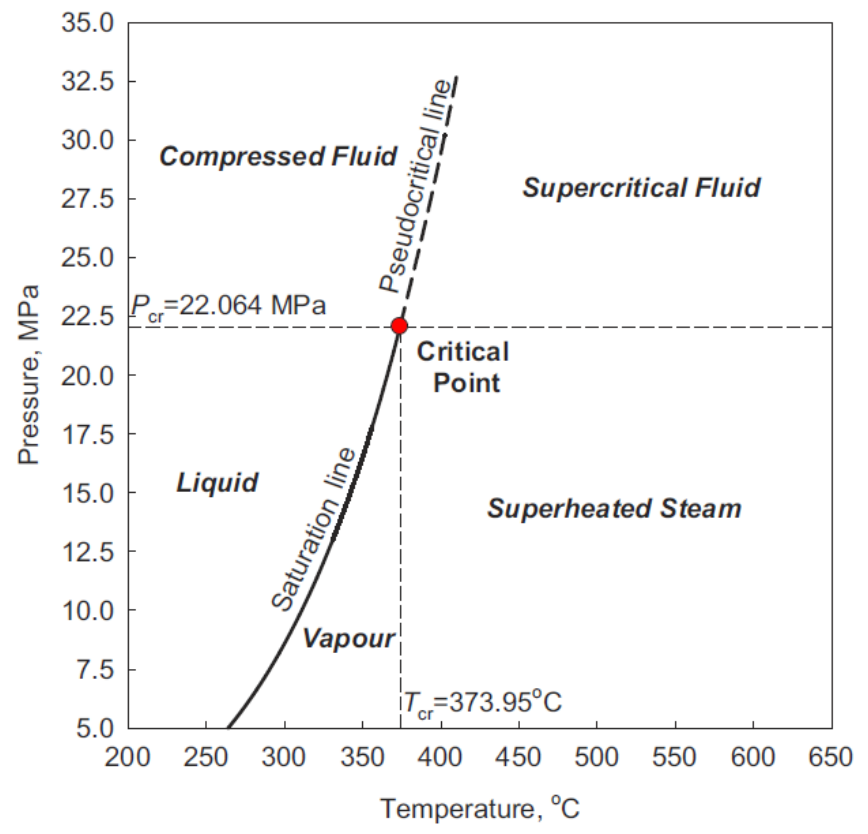

Fig. 1 Pressure-Temperature diagram of water in the critical region (Pioro \& Duffey, 2005).

Supercritical fluid is a fluid at pressures and temperatures that are higher than the critical pressure and critical temperature.

Supercritical steam ("steam") is actually supercritical water because at supercritical pressures there is no difference between phases. However, this term is widely used in literature in relation to supercritical steam generators and turbines.

Normal heat transfer (NHT) is characterized by the Heat Transfer Coefficient (HTC) is similar to those of convective heat transfer at subcritical condition that occurs far away from pseudocritical regime and are closely matches with the HTC calculated using Dittus-Boelter equation "Eq. (1)"

$N u=0.0243 \operatorname{Re}^{0.8} \mathrm{Pr}^{0.4}$

Heat transfer enhancement (HTE) is characterized by higher values of the wall heat transfer coefficient compared to those at the normal heat transfer regime and hence lower values of wall temperature within some part of a test section or within the entire test section.

Heat transfer deterioration (HTD) is characterized by lower values of the wall heat transfer coefficient compared to those at the normal heat transfer regime and hence has higher values of wall temperature within some part of a test section or within the entire test section. Fig. 2 (Pioro and Duffey, 2005) shows the variation of thermophysical properties for water at 250 bar. The large variation in properties like density, specific heat, viscosity and thermal conductivity occur within $+/-25^{\circ} \mathrm{C}$ from the pseudo-critical temperature $\left(384.9^{\circ} \mathrm{C}\right)$. This large variation influence heat transfer leading to initial heat transfer enhancement or deterioration depending on local conditions.

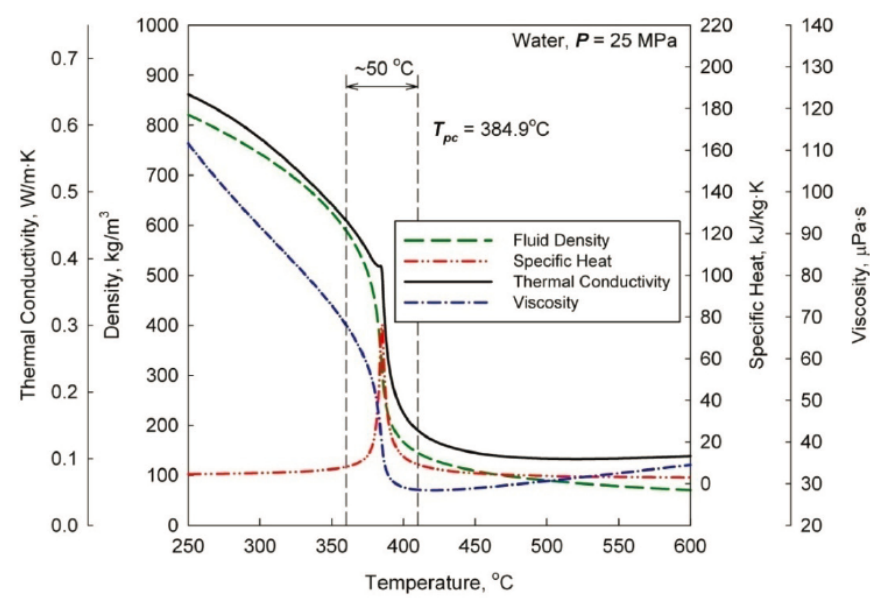

Fig. 2 Properties variation of water within pseudo-critical region at 250 bar (Pioro and Duffey, 2005).

\section{NUMERICAL METHODS}

\subsection{Geometry}

In the present work, vertical smooth tube of ID $10 \mathrm{~mm}$ and length $4 \mathrm{~m}$ has been chosen for validation for which experimental results are available in the literature Mokry et al., 2010 and Mokry et al., 2011. Therefore, the computational test parameters considered in the present work are same as experiments conducted in Mokry et al., 2010 and Mokry et al., 2011. All the simulations in the present work are carried out using ANSYS Fluent 17.2. A 2D axis symmetry geometry has been modeled and shown in Fig. 3.

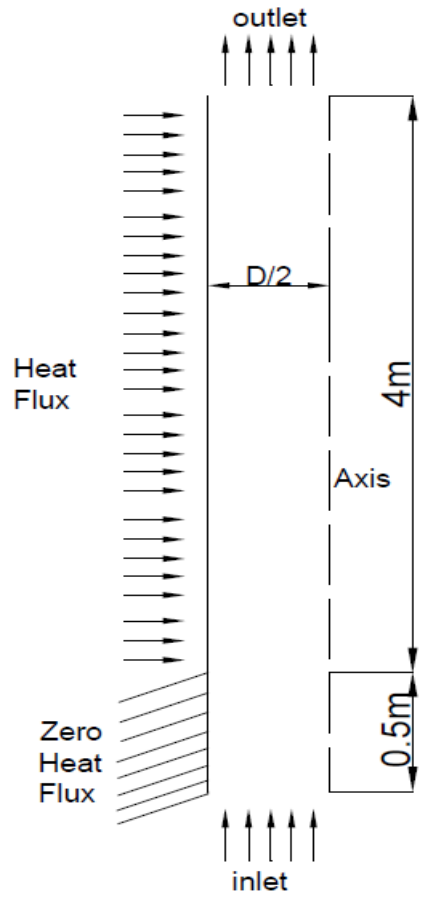

Fig. 3 Computational geometry

Since the wall temperature is uniform around the circumference of the vertical tube, a 2D model with axis-symmetry has been chosen for simulation in order to reduce the computational time. To take care of entrance effects, a $0.5 \mathrm{~m}$ of additional length is also provided without heat flux to make the flow fully developed. The physical boundary conditions of the geometry are as follows: a uniform mass flux with inlet fluid temperature is specified at the inlet and a uniform heat flux is applied around the wall boundary for the heated length and zero heat flux is applied on the unheated length of wall boundary. The pressure outlet setting in the Fluent is used as outlet boundary condition and the symmetry condition is used for the axis. 


\subsection{Governing Equations}

The basic governing equations, including the conservations of mass (continuity equation), momentum and energy, together with SST k- $\omega$ method is used to simulate the unique and complicated turbulent heat transfer characteristics at supercritical pressure (Marcin et al., 2017 and Zhi and Chen, 2011).

$\frac{\partial\left(\rho u_{i}\right)}{\partial x_{i}}=0$

$\frac{\partial\left(\rho u_{i} u_{j}\right)}{\partial x_{j}}=\rho g_{i}-\frac{\partial p}{\partial x_{i}}+\frac{\partial \tau_{i j}}{\partial x_{j}}+\frac{\partial}{\partial x_{j}}\left(-\overline{\rho u_{\imath}^{\prime} \bar{u}_{j}^{\prime}}\right)$

where,

$\tau_{i j}=\mu\left(\frac{\partial u_{i}}{\partial x_{j}}+\frac{\partial u_{j}}{\partial x_{i}}-\frac{2}{3} \delta_{i j} \frac{\partial u_{k}}{\partial x_{k}}\right)$

$\frac{\partial \rho h}{\partial t}+\frac{\partial \rho h u_{i}}{\partial x_{i}}=\frac{\partial p}{\partial t}+u_{i} \frac{\partial p}{\partial x_{i}}+\left[\mu\left(\frac{\partial u_{i}}{\partial x_{j}}+\frac{\partial u_{j}}{\partial x_{i}}\right)-\frac{2}{3} \mu \frac{\partial u_{k}}{\partial x_{k}} \delta_{i j}\right] \frac{\partial u_{i}}{\partial x_{j}}$

$+\frac{\partial}{\partial x_{i}}\left(\alpha \frac{\partial T}{\partial X_{i}}\right)+s_{h}$

$\left.s_{h}=-\overline{\left(\rho u_{\imath}^{\prime} u_{\jmath}^{\prime}\right.}\right) \frac{\partial u_{i}}{\partial u_{j}}-\frac{\partial \overline{\rho u_{\imath}^{\prime}} \overline{h^{\prime}}}{\partial x_{j}}$

$\frac{\overline{\rho u_{l}^{\prime}}}{\partial x_{j}}=-\left(\left(\frac{\mu_{t}}{\sigma_{h}}\right)\left(\frac{\partial h}{\partial x_{i}}\right)\right)$ and

the Reynolds stress term $\bar{\rho} \overline{u_{l}^{\prime}} \bar{h}$ can be presented by turbulence models. By using Boussinesq approximation, the turbulent shear stress can be found from the following equation in which Reynolds stresses are related to the average velocity gradient

$-\overline{\rho u_{\imath}^{\prime} \bar{u}_{\jmath}^{\prime}}=\mu_{t}\left(\frac{\partial u_{i}}{\partial x_{j}}+\frac{\partial u_{j}}{\partial x_{i}}-\frac{2}{3} \delta_{i j} \frac{\partial u_{k}}{\partial x_{k}}\right)-\frac{2}{3} \delta_{i j} \rho k$

where,

$\mu_{t}$ is turbulent viscosity which is flow property; not a fluid property. In the present work, SST k- $\omega$ model is used,

here, $\mu_{t}=\rho \frac{k}{\omega}$

$\mathrm{k}-\omega$ equations are derived from transport equations empirically for turbulent kinetic energy $(\mathrm{k})$ and specific turbulent dissipation rate $(\omega)$.

$\frac{\partial}{\partial t}(\rho k)+\frac{\partial}{\partial x_{i}}\left(\rho k u_{i}\right)=\frac{\partial}{\partial x_{j}}\left[\Gamma_{k} \frac{\partial k}{\partial x_{j}}\right]+G_{k}-Y_{k}+S_{k}$

and

$\frac{\partial}{\partial t}(\rho \omega)+\frac{\partial}{\partial x_{i}}\left(\rho \omega u_{i}\right)=\frac{\partial}{\partial x_{j}}\left[\Gamma_{\omega} \frac{\partial \omega}{\partial x_{j}}\right]+G_{\omega}-Y_{\omega}+S_{\omega}$

$G_{k}$-generation of turbulence kinetic energy due to mean velocity gradients, $G_{\omega^{-}}$generation of turbulence kinetic energy at $\omega$, $\mathrm{Y}_{\mathrm{M}}$ and $\mathrm{Y}_{\omega^{-}}$dissipation of $\mathrm{k}$ and $\omega, \quad \Gamma_{\mathrm{k}}$ and $\Gamma_{\omega}-$ effective diffusivity of $\mathrm{k}$ and $\omega, S_{k}, S_{\epsilon^{-}}$user defined source terms. The governing differential equations are solved using the finite volume method. The QUICK scheme is used for approximating the convection terms in momentum and energy equations. The SIMPLE procedure is chosen to couple pressure and velocity. The algebraic equations are solved with ADI methodology. As already mentioned, fluid properties also abruptly change with pressure and temperature, therefore NIST Refprop which is an inbuilt program in Fluent has been used to compute fluid properties. The simulations are stopped when the convergence criteria become less than $10^{-6}$ so as to assure the enough accuracy level. In the present work, a number of turbulence models like SST k- $\omega$, Low re - k $\varepsilon$, RNG k- $\varepsilon$, Standard k- $\varepsilon$ and Realizable models have been examined. Two numerical case studies were conducted for choosing the best turbulent models, Case I low q/G=0.27 \& Case II high $\mathrm{q} / \mathrm{G}=0.67$. In case I, heat flux $141 \mathrm{~kW} / \mathrm{m}^{2}$, mass flux $504 \mathrm{~kg} / \mathrm{m}^{2} \mathrm{~s}$ and pressure 241 bar and Case II heat flux $334 \mathrm{~kW} / \mathrm{m}^{2}$, mass flux $499 \mathrm{~kg} / \mathrm{m}^{2} \mathrm{~s}$ and pressure 241 bar were used (Mokry et al., 2011). In both studies, Mokry's et al., 2011 experimental wall temperatures was compared with wall temperature predicted by various turbulence models. Fig. 4 In case I, all the models were closely matches with experiment data. Fig. 5 In case II, where $q / G$ is high, causes heat transfer deterioration, only SST k- $\omega$ model follows the wall temperature trend with experiment data. All other models not able to predict sharp rise in wall temperature. Therefore, in the present work SST k- $\omega$ model has been used for all the computations.

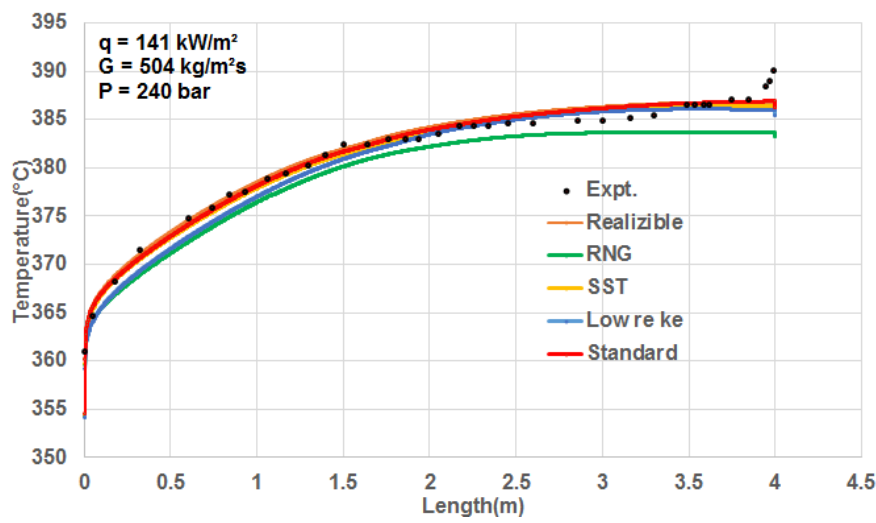

Fig. 4 Case I- comparison of various turbulent models at low $\mathrm{q} / \mathrm{G}=0.27$ (Mokry et al., 2011).

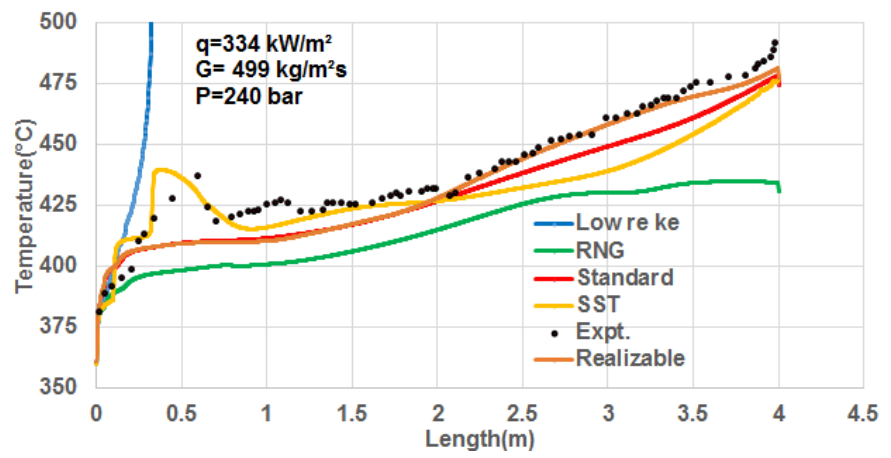

Fig. 5 Case II- comparison of various turbulent models at high $\mathrm{q} / \mathrm{G}=0.67$ (Mokry et al., 2011).

\subsection{Grid independence study and validation}

As the accuracy of results depends upon the fineness of the grid, great care is required for selecting the grid size. More fineness of the grid increases the computational time. Therefore, grid independence study has been carried out to select the appropriate size of the grid. Any further refinement of the mesh doesn't change the solution. The test has been conducted for the geometry shown in Fig. 3 with various grid size of $60 \times 1200,80 \times 1200,100 \times 1200,120 \times 1200,140 \times 1200$ (radial nodes $\times$ axial nodes). Since the change in the parameters in radial direction is larger than the axial direction, non-uniform nodes with a successive ratio of 1.02 in the radial direction to have dense mesh near the wall and uniform nodes in the axial direction were used. Fig. 6 shows the zoomed view of computational mesh to represent fine mesh near the wall and coarse mesh near the axis. The additional $0.5 \mathrm{~m}$ length (shown in Fig. 3) is separately divided in to $120 \times 300$ grid nodes. In order to choose the appropriate mesh, simulation has been carried out for the experimental operating condition of with pressure 241 bar, heat flux $141 \mathrm{~kW} / \mathrm{m}^{2}$, mass flux of $504 \mathrm{~kg} / \mathrm{m}^{2}$ with various mesh sizes (Mokry et al., 2011). The obtained wall temperature for various meshes are plotted and compared with experimental data as shown in Fig. 7. It is found that the temperature for meshes $120 \times 1200$ and $140 \times 1200$ closely matches with experimental data. Also, any further refinement of mesh does not alter the solution. Therefore $120 \times 1200$ mesh has been chosen for all the computations. In order to gain confidence, two validations have also been carried out for the pressure $241 \mathrm{bar}$, heat flux $190 \mathrm{~kW} / \mathrm{m}^{2}$ and mass flux $498 \mathrm{~kg} / \mathrm{m}^{2} \mathrm{~s} \&$ pressure 241 bar, heat flux $334 \mathrm{~kW} / \mathrm{m}^{2}$ and mass flux $499 \mathrm{~kg} / \mathrm{m}^{2} \mathrm{~s}$. Wall temperature is plotted against the length of the tube and compared with experimental wall temperature of represented in Fig. 8.(Mokry et al.,2010) \& Fig. 9 (Mokry et al.,2011). These shows that the present simulation model is appropriate. 


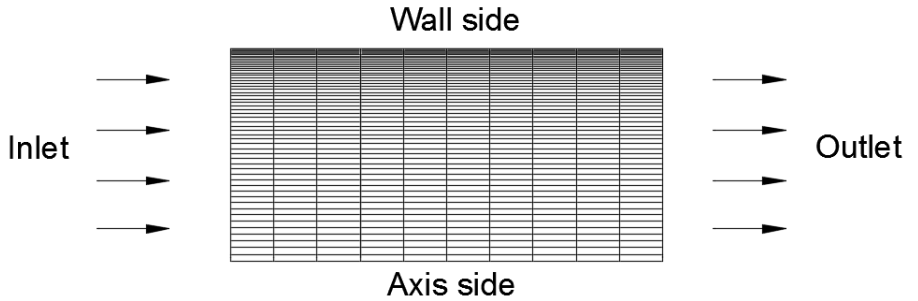

Fig. 6 Zoomed view of computational mesh

\section{RESULTS AND DISCUSSION}

\subsection{Experiment based empirical correlations in literature}

For predicting the heat transfer in turbulent convective heat transfer and for heat transfer at supercritical conditions, following experiment based empirical correlations are available in literature. Dittus - Boelter (1930) introduced a heat-transfer correlation at subcritical pressure for forced convection which is still universally used and is given by

$N u_{b}=0.023 \operatorname{Re}_{b}^{0.8} \operatorname{Pr}_{b}^{0.4}$

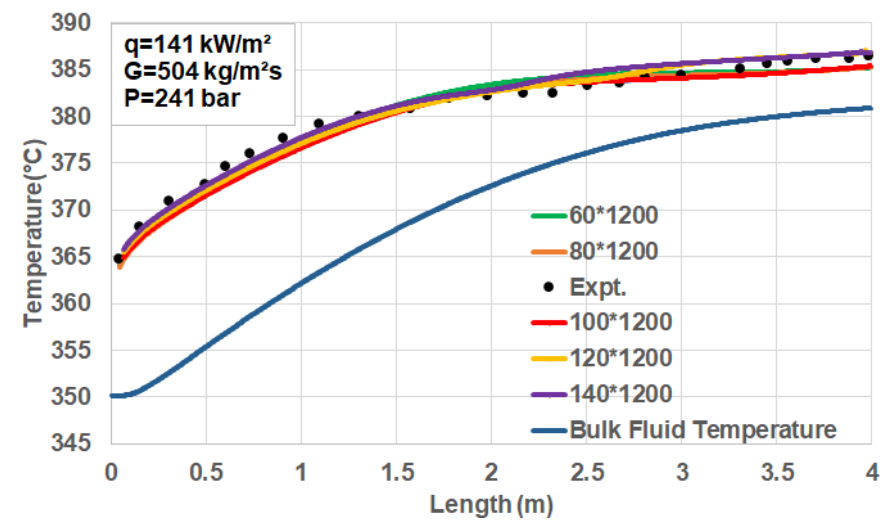

Fig. 7 Grid independence study for the case of pressure 241 bar, mass flux $504 \mathrm{~kg} / \mathrm{m}^{2} \mathrm{~s}$, heat flux $141 \mathrm{~kW} / \mathrm{m}^{2}$ (Mokry et al., 2011).

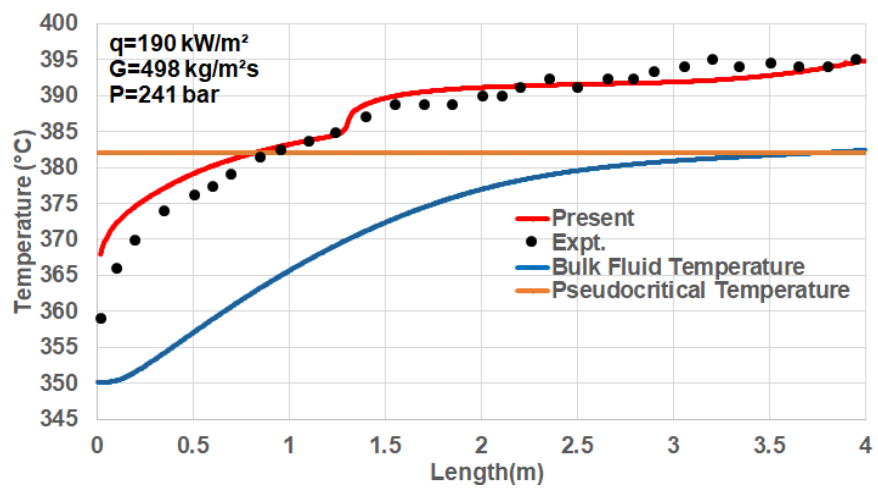

Fig. 8 Validation of present numerical simulation with experimental result of Mokry et al. (2010) for $\mathrm{q} / \mathrm{G}=0.38$.

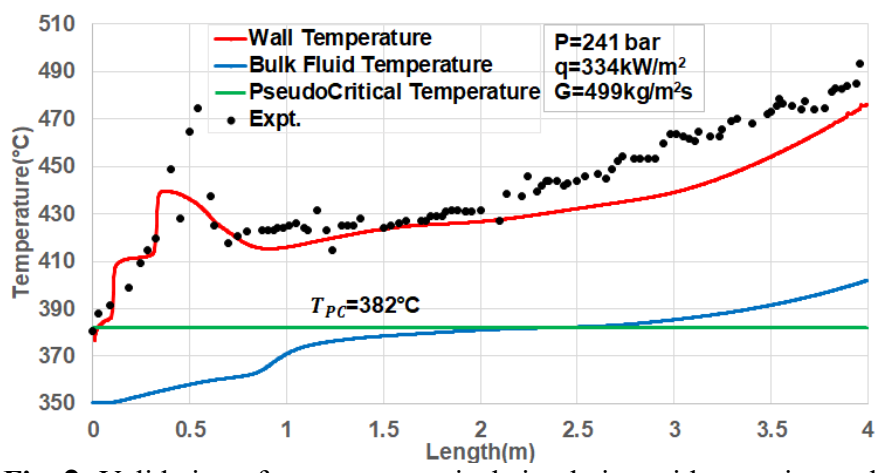

Fig. 9 Validation of present numerical simulation with experimental result of Mokry et al. (2011) for $\mathrm{q} / \mathrm{G}=0.67$.
McAdams (1942) proposed to use the Dittus - Boelter (1930) equation in the following form for forced convective heat transfer in turbulent flows

$N u_{b}=0.0243 \operatorname{Re}_{b}^{0.8} \operatorname{Pr}_{b}^{0.4}$

Bishop et al. (1964) conducted experiments in supercritical water flowing upward inside bare tubes in the following range of operating parameters: $\mathrm{P}=228-276$ bar, $\mathrm{T}_{\mathrm{b}}=282-527^{\circ} \mathrm{C}, \mathrm{G}=651-3662 \mathrm{~kg} / \mathrm{m}^{2}$ $\mathrm{s}$, and $\mathrm{q}=0.31$ to $3.46 \mathrm{MW} / \mathrm{m}^{2}$ and proposed the following equation

$N u_{x}=0.0069 \operatorname{Re}_{x}^{0.9} \overline{P r_{x}^{0.66}}\left(\frac{\rho_{w}}{\rho_{b}}\right)_{x}^{0.43}\left(1+2.4 \frac{D}{x}\right)$

Shitsman, (1968) analyzed the heat transfer experimental data of supercritical water flowing inside tubes and then generalized these data with the Dittus-Boelter type correlation:

$N u_{b}=0.023 R e_{b}^{0.8} \operatorname{Pr}_{\min }^{0.8}$

The subscript "min" means minimum Pr value, i.e., either the Pr value evaluated at the bulk fluid temperature or the Pr value evaluated at the wall temperature.

Ornatsky et al. (1971) performed an experiment and recommended the following correlation:

$N u=0.023 R e^{0.8} \operatorname{Pr}_{\min }^{0.8}\left(\frac{\rho_{w}}{\rho_{b}}\right)^{0.3}$

Yamagata et al. (1972) performed an experiment and recommended the following correlation:

$N u_{b}=0.0135 \operatorname{Re}_{b}^{0.85} \operatorname{Pr}_{b}^{0.8} F_{c}$,

where $F_{c}=1.0$ for $E>1, F_{c}=0.67 \operatorname{Pr}_{p c}-0.05\left(c \bar{p} / c_{p b}\right)^{n_{1}}$ for $0<E<1$.

$F c=\left(c p / c_{p b}\right)^{n_{2}}$ for $E<0$

$n_{1}=-0.77\left(1+1 / P r_{m}\right)-0.53$ and $n_{2}=1.44\left(1+1 / P r_{m}\right)-0.53$

Jackson and Hall (1979) performed experimental investigations of heat transfer to supercritical carbon dioxide in both upward and downward directions in a vertical circular tube and arrived at a correlation given below

$$
N u=0.0183 \operatorname{Re}_{b}^{0.82} \overline{\operatorname{Pr}} 0.5\left(\frac{\rho_{w}}{\rho_{b}}\right)^{0.3}\left(\frac{\overline{c_{p}}}{c_{p b}}\right)^{n}
$$

Where, $n=0.4$ for $T_{b}<T_{w}$ and for $1.2 T_{p c}<T_{b}<T_{w}$

$n=0.4+0.2\left(\frac{T_{w}}{T_{p c}}-1\right)$ for $T_{b}<T_{p c}<T_{w}$

$n=0.4+0.2\left(\frac{T_{w}}{T_{p c}}-1\right)\left[1-5\left(\frac{T_{b}}{T_{p c}}-1\right)\right]$ for $T_{p c}<T_{b}$
$<1.2 T_{p c}$ and $T_{b}<T_{w}$

Watts and Chou (1982) developed an empirical correlation for vertical upward and downward flow .For the vertical upward flow, the correlation takes the form :

$N u_{b}=\left\{\begin{array}{c}N u_{v a r}(7000 \varphi)^{0.295}, \text { if } 10^{-4} \leq \varphi \\ N u_{v a r}(1-3000 \varphi)^{0.295}, \text { if } 10^{-5} \leq \varphi \leq 10^{-4}\end{array}\right.$
$N u_{\text {var }}=0.021 \operatorname{Re}_{b}^{0.8} \overline{\operatorname{Pr}^{0.55}}\left(\frac{\rho_{w}}{\rho_{b}}\right)^{0.35}$

and the buoyancy parameter is defined as $\varphi=\bar{G} r_{b} /\left(R e_{b}^{2.7} \overline{P r_{b}^{0.5}}\right)$

Griem (1996) presented correlation for forced convection heat transfer at critical and supercritical pressures in tubes in the following form:

$N u_{b}=0.0169 R e_{b}^{0.8356} \operatorname{Pr}_{b}^{0.432}$

Zhu et al. (2009) investigated the heat transfer characteristics of steamwater two-phase flow in vertical upward tube in the range of pressure from 90 to 300 bar, mass velocity from 600 to $1200 \mathrm{~kg} /\left(\mathrm{m}^{2} \mathrm{~s}\right)$, and heat flux at inner wall from 200 to $600 \mathrm{~kW} / \mathrm{m}^{2}$ and provided a Nusselt number correlation as

$N u_{b}=0.0068 R e_{b}^{0.90}{\overline{P r_{b}}}^{0.63}\left(\frac{\rho_{w}}{\rho_{b}}\right)^{0.17}\left(\frac{k_{w}}{k_{b}}\right)^{0.29}$

Mokry et al. (2011) developed an empirical correlation in supercritical water flowing upward in a $10 \mathrm{~mm}$ diameter tube at 240 bar, inlet temperature from 320 to $350{ }^{\circ} \mathrm{C}$, mass flux ranged from 200 to 1500 
$\mathrm{kg} / \mathrm{m}^{2} \mathrm{~s}$ and heat fluxes up to $1250 \mathrm{~kW} / \mathrm{m}^{2}$. The final form of correlation is given below

$N u_{b}=0.0061 R e_{b}^{0.904} \overline{P r}_{b}^{0.684}\left(\frac{\rho_{w}}{\rho_{b}}\right)^{0.564}$

\subsection{Comparison of metal temperature predictions by CFD} and empirical correlations

In an effort to make the evaluation of CFD and correlations, an experimental data from Mokry et al., 2010 \& Mokry et al., 2011 having 362 data points were selected. The selected data points cover a mass flux range of $300-1600 \mathrm{~kg} / \mathrm{m}^{2} \mathrm{~s}$, a heat flux range of $150-1000$ $\mathrm{kW} / \mathrm{m}^{2}$, a pressure 240 bar and a diameter $10 \mathrm{~mm}$. Out of 362 data points, 141 data points belongs to heat transfer enhancement and 221 data points belong to heat transfer deterioration. First, the experimental conditions are numerically simulated using CFD and 11 correlations identified from the literature are evaluated in the interest of determining the best correlation for the upward vertical flow at the supercritical pressure.

\subsection{Comparison of CFD and correlations predictions with experimental data for heat transfer enhancement zone.}

The selected 141 experimental data obtained from the literature for the heat transfer enhancement zone is shown in Table 1. It covers the range of the heat flux and mass flux ratio from 0.27 to 0.48 .

Table 1 shows the heat flux and mass flux details for the heat transfer enhancement zone.

\begin{tabular}{|l|c|c|c|c|c|c|}
\hline $\begin{array}{l}\text { SI.N } \\
\text { o }\end{array}$ & $\begin{array}{l}\text { Diamet } \\
\mathbf{e r} \\
(\mathbf{m m})\end{array}$ & $\begin{array}{l}\text { Heat flux } \\
\mathbf{( q )} \\
\mathbf{k W} / \mathbf{m}^{2}\end{array}$ & $\begin{array}{l}\text { Mass } \\
\mathbf{f l u x ( G )} \\
\mathbf{k g} / \mathbf{m}^{2} \mathbf{s}\end{array}$ & $\begin{array}{l}\text { Pressu } \\
\text { re(bar) }\end{array}$ & $\begin{array}{l}\mathbf{q} / \mathbf{G} \\
\text { ratio }\end{array}$ & $\begin{array}{l}\text { Data } \\
\text { points } \\
\text { (nos) }\end{array}$ \\
\hline 01 & 10 & 141 & 504 & 241 & 0.279 & 29 \\
\hline 02 & 10 & 190 & 498 & 241 & 0.38 & 33 \\
\hline 03 & 10 & 590 & 1503 & 241 & 0.39 & 34 \\
\hline 04 & 10 & 484 & 1002 & 241 & 0.48 & 45 \\
\hline
\end{tabular}

The wall temperature predictions obtained by CFD and correlations were compared with the 141 experimental data points belonging to heat transfer enhancement zone as summarized in Table 2 (shown in Appendix). In the present work, 11 established correlations such as Dittus- Boelter, 1930; McAdams, 1942; Griem, 1996; Jackson and Hall, 1979; Shitsman 1968; Bishop et al., 1964; Yamagata et al., 1972; Mokry et al., 2011; Zhu et al., 2009; Watts \& Chou, 1982 and Ornatsky et al., 1971 were chosen for comparison. A visual basic code had been developed for predicting the wall temperature using correlations and for ranking the correlations and CFD predictions based on their prediction accuracies. Table 2 provides the wall temperature predicted by CFD and six correlations during heat transfer enhancement conditions. Table 3 provides the ranking information of CFD and empirical correlations on wall temperature prediction accuracies based on number of wall temperature points deviated with 141 experimental data points covering pseudocritical region where there is heat transfer enhancement (no heat transfer deterioration). Among the 11 correlations, Zhu et al. (2009), Jackson and Hall, (1974) and Mokry et al. (2011) shows the best agreement with 141 nos of data points, followed by Watts and Chou, (1982), Shitsman, (1968) and CFD correlations with 139,138 and 137 number of data points at less than $+/-3^{\circ} \mathrm{C}$ error level respectively. It is found that the CFD predictions have better agreement with 141 number of experimental data points with $100 \%$ of the predictions at less than $+/-5^{\circ} \mathrm{C}$ error level. Fig. 10 provides the histogram of CFD and empirical correlations on wall temperature prediction accuracy based on percentage of error deviation in comparison with 141 experimental data points covering pseudo critical region where there is heat transfer enhancement (no heat transfer deterioration). Among the 11 correlations, CFD shows the best agreement with 141 number of experimental data points at less than $+/ 5{ }^{\circ} \mathrm{C}$ error level, along with Yamagata et al. (1972); Bishop et al. (1964); Watts and Chou (1982); Shitsman (1968); McAdams (1942) and Griem (1996) correlations with $100 \%$ of predictions. Fig. 11 depicts the comparison of wall temperature predicted by CFD and Mokry et al., (2011) correlation with experimental data for a typical heat transfer enhancement case. It is found that, wall temperature predicted by both correlation and CFD are closely matches with experimental data. This is due to absence of non-linearity behavior of wall temperature.

Table 3 Typical comparison of wall temperatures predicted by CFD and selected correlations with 141 experimental data of Mokry et al. (2011) (for heat transfer enhancement zone) in percentage.

\begin{tabular}{|c|c|c|c|c|c|}
\hline \multirow[t]{2}{*}{ Sl.no } & \multirow[t]{2}{*}{$\begin{array}{l}\text { Correlations } \\
\text { ranking }\end{array}$} & \multicolumn{4}{|c|}{$\begin{array}{l}\text { Comparison of wall temperature predictions } \\
\text { by CFD and Various correlations with expt. } \\
\text { (data points in nos) }\end{array}$} \\
\hline & & $< \pm 7 \%$ & $< \pm 5 \%$ & $< \pm 3 \%$ & $< \pm 1 \%$ \\
\hline 1 & Mokry & 0 & 0 & 141 & 106 \\
\hline 2 & Jackson & 0 & 0 & 141 & 106 \\
\hline 3 & Mcadams & 0 & 141 & 130 & 93 \\
\hline 4 & Watts \& Chou & 0 & 141 & 139 & 91 \\
\hline 5 & Griem & 0 & 141 & 119 & 90 \\
\hline 6 & Dittus & 0 & 141 & 132 & 83 \\
\hline 7 & Shitsman & 0 & 141 & 138 & 82 \\
\hline 8 & Ornatsky & 141 & 139 & 20 & 74 \\
\hline 9 & CFD & 0 & 141 & 137 & 70 \\
\hline 10 & Zhu & 0 & 0 & 141 & 69 \\
\hline 11 & Bishop & 0 & 141 & 140 & 62 \\
\hline 12 & Yamagata & 0 & 141 & 122 & 42 \\
\hline
\end{tabular}

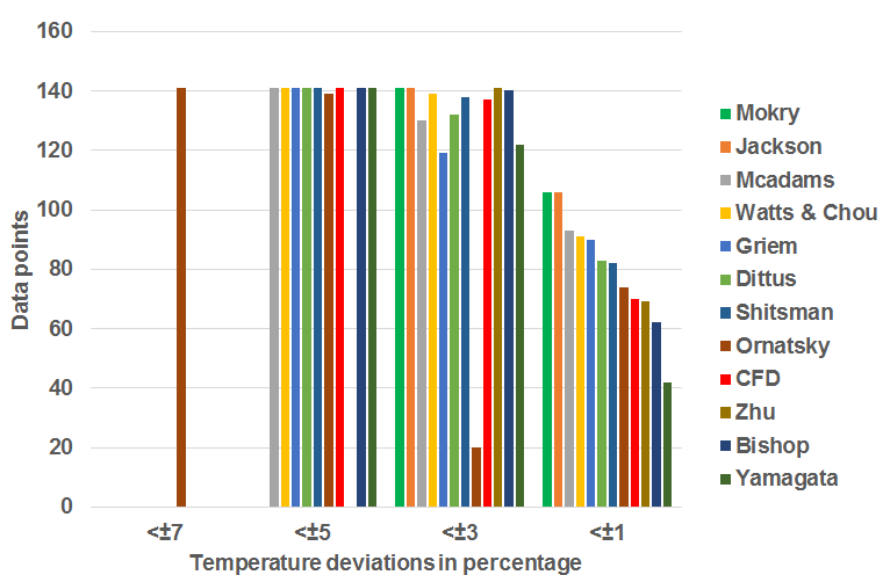

Fig. 10 Histogram for comparing the 141 experimental data with 11 correlations in the heat transfer enhancement zone.

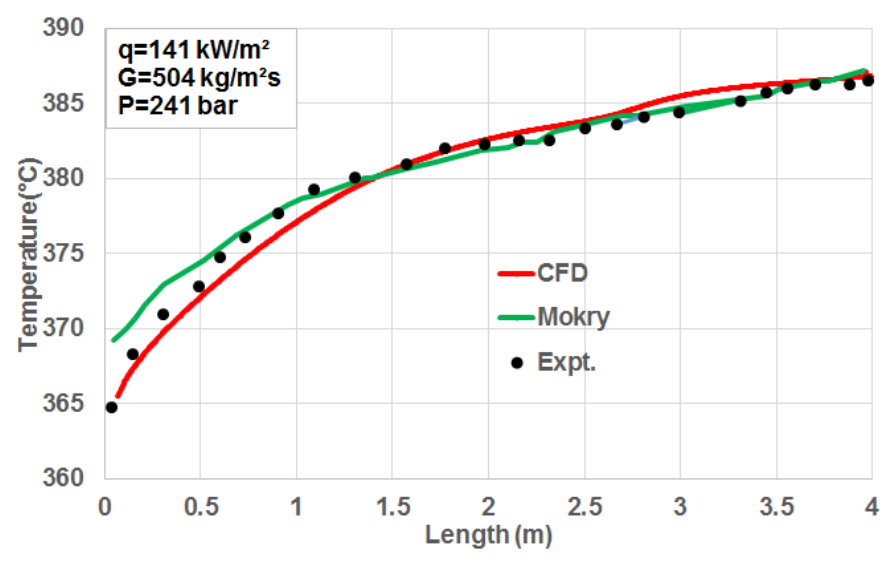

Fig. 11 Comparison of wall temperature predicted by CFD and by Mokry et al. (2011)'s Correlation for mass flux with that of experiment.

\subsection{Comparison of CFD and correlations predictions with experimental data for heat transfer deterioration zone}

The selected 221 experimental data points obtained from the literature for the heat transfer deteriorated zone is shown in Table 4. It covers the range of the heat flux and mass flux ratio from 0.58 to 0.83 . 
Table 4 shows the heat flux and mass flux details for the heat transfer deterioration zone.

\begin{tabular}{|c|c|c|l|l|l|l|}
\hline $\begin{array}{l}\text { Sl. } \\
\text { No }\end{array}$ & $\begin{array}{l}\text { Diam } \\
\text { eter( } \\
\mathbf{m m})\end{array}$ & $\begin{array}{l}\text { Heat } \\
\text { flux (q) } \\
\mathbf{k W} / \mathbf{m}^{\mathbf{2}}\end{array}$ & $\begin{array}{l}\text { Mass } \\
\mathbf{f l u x ( G )} \\
\mathbf{k g} / \mathbf{m}^{\mathbf{2}} \mathbf{s}\end{array}$ & $\begin{array}{l}\text { Pressur } \\
\text { e(bar) }\end{array}$ & $\begin{array}{l}\mathbf{q} / \mathbf{G} \\
\text { ratio }\end{array}$ & $\begin{array}{l}\text { Data } \\
\text { points } \\
\text { (nos) }\end{array}$ \\
\hline 01 & 10 & 289 & 499 & 241 & 0.58 & 43 \\
\hline 02 & 10 & 334 & 499 & 241 & 0.67 & 63 \\
\hline 03 & 10 & 686 & 994 & 241 & 0.69 & 30 \\
\hline 04 & 10 & 166 & 206 & 241 & 0805 & 39 \\
\hline 05 & 10 & 826 & 1000 & 241 & 0.83 & 46 \\
\hline
\end{tabular}

The wall temperature predictions obtained by CFD and 11 correlations were compared with the 221 experimental data points belonging to heat transfer deterioration zone as summarized in Table 5 (shown in Appendix). Table 6 provides the ranking information of CFD and empirical correlations on wall temperature prediction accuracies based on number of wall temperature points deviated with 221 experimental data points covering pseudocritical region where there is heat transfer deterioration. Table 6 provides the histogram ranking information of CFD and empirical correlations on wall temperature prediction accuracy based on percentage of error deviation in comparison with 221 experimental data points covering pseudocritical region where there is heat transfer deterioration. Among the 11 correlations, CFD shows the best agreement at less than $+/-1^{\circ} \mathrm{C}$ error level followed by Zhu et al. (2009); Ornatsky et al. (1971); Jackson and Hall (1979) and Mokry et al. (2011) correlations. At less than $+/-3^{\circ} \mathrm{C}$ level, Zhu et al. (2009) predicts 147 data points. At less than $+/-5^{\circ} \mathrm{C}$ level, Zhu et al. (2009) predicts 192 number of data points accurately and followed by CFD and Watts and Chou (1982) with 171 \& 165 data points respectively. At less than $+/-7^{\circ} \mathrm{C}$ level, Zhu et al. (2009) predicts 205 number of data points accurately and followed by CFD, Watts and Chou (1982) with $190 \& 188$ data points respectively. At less than $+/-10^{\circ} \mathrm{C}$ level, Zhu et al. (2009) predicts 211 number of data points accurately and followed by CFD, Watts and Chou (1982) with 208 data points. Among the 11 correlations, Zhu et al. (2009) shows the best agreement at less than $+/-10^{\circ} \mathrm{C},+/-7^{\circ} \mathrm{C},+/-5^{\circ} \mathrm{C}$ and $+/-$ $3^{\circ} \mathrm{C}$ error level followed by CFD, Watts and Chou (1982) and Mokry et al. (2011) correlations.

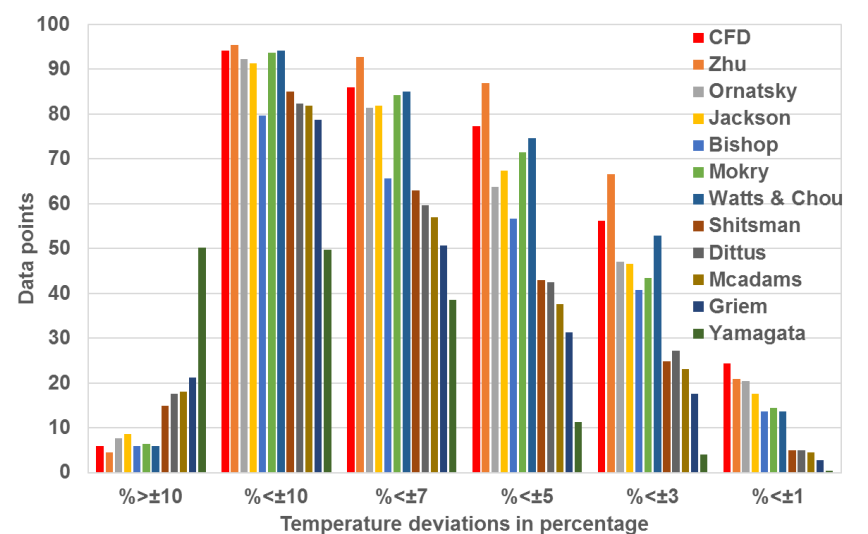

Fig. 12 Histogram for comparing the 221 experimental data with 11 correlations in the deteriorated heat transfer zone.

At less than $+/-3^{\circ} \mathrm{C}$ level, Zhu et al. (2009) predicts 147 of data points accurately and followed by CFD and Watts \& Chou with $124 \&$ 117 data points respectively. It is also found that the CFD predictions have best agreement with experimental data at less than $+/-1^{\circ} \mathrm{C}$ error level with 54 data points of the predictions and followed by Zhu et al. (2009) and Ornatsky et al. (1971) with 46 and 45 data points respectively. Fig. 12 provides the histogram of CFD and empirical correlations on wall temperature prediction accuracy based on percentage of error deviation in comparison with 221 experimental data points covering pseudocritical region where there is heat transfer deterioration. CFD shows best agreement with experimental data at less than $+/-1 \%$ and better agreement with experiment data at $+/-10^{\circ} \mathrm{C}$, $+/-7{ }^{\circ} \mathrm{C},+/-5^{\circ} \mathrm{C}$ and $+/-3^{\circ} \mathrm{C}$. Fig. 13 depicts the comparison of wall temperature predicted by CFD and Zhu et al. (2009)'s correlation with experimental data (Mokry et al., 2011) for a typical heat transfer deterioration case. It is found that, unlike correlations prediction, the sudden rise in temperature is clearly predicted by CFD.

Table 6 Typical comparison of wall temperatures predicted by CFD and selected correlations with 221 experimental data (for heat transfer deterioration zone) in percentage.

\begin{tabular}{|c|c|c|c|c|c|c|c|}
\hline \multirow[t]{2}{*}{$\begin{array}{c}\text { Sl.n } \\
\text { o }\end{array}$} & \multirow{2}{*}{$\begin{array}{l}\text { Correlatio } \\
\text { ns ranking }\end{array}$} & \multicolumn{6}{|c|}{$\begin{array}{c}\text { Comparison of wall temperature predictions by } \\
\text { CFD and various correlations with expt. (data } \\
\text { points in nos) }\end{array}$} \\
\hline & & $\begin{array}{c}> \pm 10 \\
\%\end{array}$ & $\begin{array}{c}< \pm 10 \\
\%\end{array}$ & $\begin{array}{l}< \pm 7 \\
\%\end{array}$ & $\begin{array}{l}< \pm 5 \\
\%\end{array}$ & $\begin{array}{c}< \pm 3 \\
\%\end{array}$ & $\begin{array}{c}< \pm 1 \\
\%\end{array}$ \\
\hline 1 & CFD & 13 & 208 & 190 & 171 & 124 & 54 \\
\hline 2 & Zhu & 10 & 211 & 205 & 192 & 147 & 46 \\
\hline 3 & Ornatsky & 17 & 204 & 180 & 141 & 104 & 45 \\
\hline 4 & Jackson & 19 & 202 & 181 & 149 & 103 & 39 \\
\hline 5 & Mokry & 14 & 207 & 186 & 158 & 96 & 32 \\
\hline 6 & Bishop & 13 & 176 & 145 & 125 & 90 & 30 \\
\hline 7 & $\begin{array}{l}\text { Watts \& } \\
\text { Chou }\end{array}$ & 13 & 208 & 188 & 165 & 117 & 30 \\
\hline 8 & Shitsman & 33 & 188 & 139 & 95 & 55 & 11 \\
\hline 9 & Dittus & 39 & 182 & 132 & 94 & 60 & 11 \\
\hline 10 & Mcadams & 40 & 181 & 126 & 83 & 51 & 10 \\
\hline 11 & Griem & 47 & 174 & 112 & 69 & 39 & 6 \\
\hline 12 & Yamagata & 111 & 110 & 85 & 25 & 9 & 1 \\
\hline
\end{tabular}

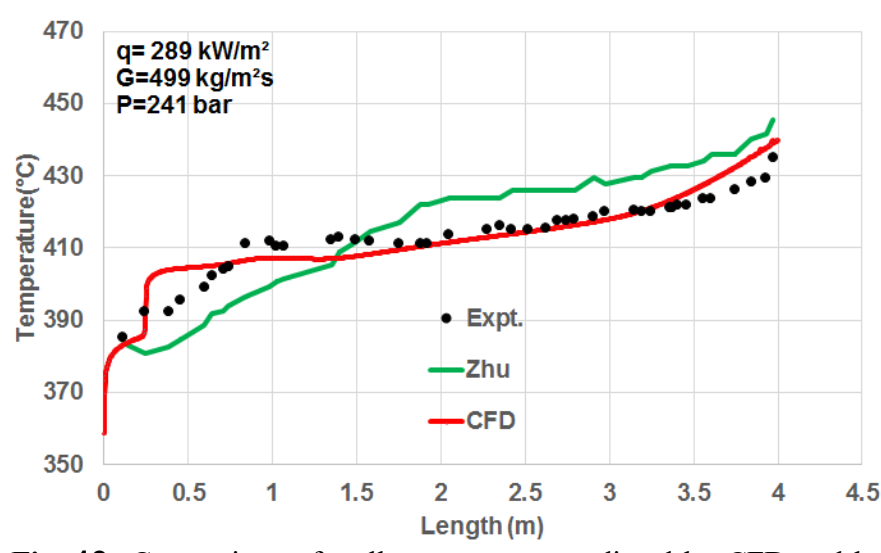

Fig. 13 Comparison of wall temperature predicted by CFD and by Zhu et al. (2009)'s correlation for mass flux with that of experiment Mokry et al. (2011).

\section{CONCLUSIONS}

The present work investigates the heat transfer in supercritical fluids by CFD and compares its prediction with various correlations available in literature. A two-dimensional axis-symmetric model has been considered. In order to evaluate the accuracy of the present model, the experimental data available in literature has been selected for validation. The computational domain is discretized with a nonuniform mesh of 120 nodes along the radial direction and 1200 uniform nodes along the axial direction after performing grid independency test. It is found that SST k- $\omega$ model captures heat transfer behavior at both enhancement and deterioration regions when compared with other turbulence models. A 362 experimental data have been taken from various literatures covering normal, heat transfer enhancement and heat transfer deterioration regimes for studying the capability of wall temperature prediction by CFD and various empirical correlations available in the literature. It is observed that under heat transfer enhancement zone the prediction accuracy by CFD based on wall temperature deviation and percentage error of wall temperature is the best along with Zhu et al. (2009), Mokry et al., (2011) and Jackson and Hall (1974). At heat transfer deterioration zone, the prediction accuracy by CFD based on wall temperature 
prediction $\left({ }^{\circ} \mathrm{C}\right)$ is the best. None of the empirical correlations capable to predict the sharp gradient. Thus CFD can be used an alternate tool to predict the wall temperature and study the heat transfer characteristics (heat transfer deterioration and heat transfer enhancement) near pseudo critical region accurately.

\section{NOMENCLATURE}

$\begin{array}{ll}b & \text { Bulk fluid temperature }\left({ }^{\circ} \mathrm{C}\right) \\ B u & \text { Buoyancy } \\ C_{P} & \text { Specific heat constant pressure }(\mathrm{J} / \mathrm{kg} / \mathrm{k}) \\ G & \text { Mass flux }\left(\mathrm{kg} / \mathrm{m}^{2} \mathrm{~s}\right) \\ G_{r} & \text { Grashof number } \\ h & \text { Heat transfer coefficient }\left(\mathrm{kW} / \mathrm{m}^{2}\right) \\ i, j & \text { Direction of vectors } \\ q & \text { Heat flux }\left(\mathrm{kW} / \mathrm{m}^{2}\right) \\ q_{c} & \text { Limit heat flux }\left(\mathrm{kW} / \mathrm{m}^{2}\right) \\ N u & \text { Nusselt number } \\ P r & \text { Prandtl number } \\ R e & \text { Reynolds number } \\ T_{p c} & \text { Pseudocritical temperature }\left({ }^{\circ} \mathrm{C}\right) \\ u & \text { Velocity component }(\mathrm{m} / \mathrm{s}) \\ G r e e k & \text { symbols } \\ \rho & \text { Density }\left(\mathrm{kg} / \mathrm{m}^{3}\right) \\ k & \text { Turbulent kinetic energy }\left(\mathrm{m}^{2} / \mathrm{s}^{2}\right) \\ \omega & \text { Specific turbulence dissipation rate }(1 / \mathrm{s}) \\ \mu_{t} & \text { Turbulent viscosity }(\mathrm{kg} / \mathrm{m} / \mathrm{s}) \\ \varepsilon & \text { Rate of dissipation of k }\left(\mathrm{m}^{2} / \mathrm{s}^{3}\right) \\ \tau & \text { Shear stress }\left(\mathrm{kg} / \mathrm{m} / \mathrm{s}^{2}\right) \\ A b b r e v i a t i o n s \\ C F D & \text { Computational Fluid Dynamics } \\ H T E & \text { Heat Transfer Enhancement } \\ H T C & \text { Heat Transfer Coefficient } \\ H T D & \text { Heat Transfer Deterioration } \\ N H T & \text { Normal Heat Transfer } \\ S C & \text { Supercritical } \\ S S T & \text { Shear Stress Transport } \\ & \end{array}$

\section{REFERENCES}

Bishop, A.A., Krambeck, F.J., and Sandberg, R.O., 1964, "High temperature supercritical water loop -PART III- Forced convection heat transfer to superheated steam at high pressure and high Prandtl numbers," Westinghouse, WCAP-2056.

Cheng, X., Schulenberg, T., Bittermann, D., and Rau, P., 2003, "Design analysis of core assembly for supercritical pressure conditions" Nucl. Eng. Des, 223, 279-294.

https://doi.org/10.1016/S0029-5493(03)00059-1

Dittus, F.W., and Boelter, L.M.K., 1930, "Heat transfer in automobile radiators of the tubular type," University of California Publications in Engineering, 2, 443.

https://doi.org/10.1016/0735-1933(85)90003

Griem, H., 1996, "A new procedure for the prediction of forced convection heat transfer at near- and supercritical pressure," Heat and Mass Transfer (Warmeund Stoffubertragung), Springer-Verlag Publishing House, 31 (5), 301-305.

Jackson J., and Hall W., 1979, "Forced convection heat transfer to fluids at supercritical pressure," Turbulent Forced Convection in Channels Hemisphere Publishing Corp and Bundles, New York, NY, USA, 563-611.
Jaromin.M., and Anglart, H., 2013, “A numerical study of heat transfer to supercritical water flowing upward in vertical tubes under normal and deteriorated conditions," Nuclear Engineering and Design, 264, $61-70$.

https://doi.org/10.1016/j.nucengdes.2012.10.028

McAdams, W.H., 1942, "Heat Transmission," 2nd edition, McGrawHill, New York, NY, USA, 459 pages.

Mokry, Pioro, Kirillov, and Gospodinov., 2010, "SC water heat transfer in a vertical bare tube," Nuclear Engineering and Design, 240, 568-576.

https://doi.org/10.1016/j.nucengdes.2009.09.003

Mokry, S., Pioro, I., Farah, A., King, K., Gupta, S., Peiman., W and Kirillov, P., 2011, "Development of supercritical water heat transfer correlation for vertical bare tubes," Nuclear Engg. Design, 241, 11261136.

http://dx.doi.org/10.1016/j.nucengdes.2010.06.012

Marcin Karol Rowinski, Jiyun Zhao, Timothy John White, Yeng Chai Soh., 2017, "Numerical investigation of supercritical water flow in a vertical pipe under axially non-uniform heat flux," Progress in Nuclear Energy, 97, 11-25.

https://doi.org/10.1016/j.pnucene.2016.12.009

Ornatskij, A.P., Glushchenko, L.F., and Kalachev, S.I., 1971, "Heat transfer with rising and falling flows of water in tubes of small diameter at supercritical pressures," Therm. Eng., 18(5),137-141.

Pioro, I. L., and Duffey, R.B., 2005, "Experimental heat transfer in supercritical water flowing inside channels (survey)," Nucl. Eng. Des, 235, 2407-2430.

https://doi.org/10.1016/j.nucengdes.2005.05.034

Shitsman, M.E., 1968, "Temperature conditions in tubes at supercritical pressures," Thermal Engineering, 15(5), 72.

Tao Zhi, Cheng Zeyuan, Zhu Jianqin and Li Haiwang., 2016, "Effect of turbulence models on predicting convective heat transfer to hydrocarbon fuel at supercritical pressure," Chinese Journal of Aeronautics, 29(5), 1247-1261.

https://doi.org/10.1016/j.cja.2016.08.007

Watts, M.J., and Chou, C.T., 1982, "Mixed convection heat transfer to supercritical pressure water," Proceedings of the 7th International Heat Transfer Conference, Munchen, Germany, 3(6-10), 495-500.

Wen, Q.L., and Gu, H.Y., 2010, "Numerical simulation of heat transfer deterioration phenomenon in supercritical water through vertical tube," Annals of Nuclear Energy, 37, 272-1280. https://doi.org/10.1016/j.anucene.2010.05.022

Yamagata, K., Nishikawa, K., and Hasegawa, S., 1972, "Forced convective heat transfer to supercritical water flowing in tubes," International Journal of Heat \& Mass Transfer, 15 (12), 2575-2593. https://doi.org/10.1016/0017-9310(72)90148-2

Zhu, X., Bi, Q., Yang, D., and Chen, T., 2009, “An investigation on heat transfer characteristics of different pressure steam-water in vertical upward tube," Nuclear Engg. Design, 239, 381-388. https://doi.org/ 10.1016/j.nucengdes.2008.10.026

Zhi Shang, and Shuo Chen., 2011, "Numerical investigation of diameter effect on heat transfer of supercritical water flows in horizontal round tubes," Applied Thermal Engineering, 31, 573-581. https://doi.org/10.1016/j.applthermaleng.2010.10.020 


\section{Appendix:}

Table 2 Typical comparison of wall temperatures predicted by CFD and selected correlations with experimental data of Mokry et al., (2011) (for heat transfer enhancement Zone).

\begin{tabular}{|c|c|c|c|c|c|c|c|c|c|c|c|c|c|}
\hline \multirow[b]{2}{*}{ SI.No } & \multirow[b]{2}{*}{$\begin{array}{c}\text { Length } \\
\text { (m) }\end{array}$} & \multirow[b]{2}{*}{$\begin{array}{c}\text { Mass } \\
\operatorname{Flux}(G) \\
\mathbf{k g} / \mathbf{m}^{2} \mathbf{s}\end{array}$} & \multirow[b]{2}{*}{$\begin{array}{l}\text { Heat Flux } \\
\text { (q) } \mathrm{kW} / \mathrm{m}^{2}\end{array}$} & \multirow[b]{2}{*}{$\mathbf{q} / \mathbf{G}$} & \multirow[b]{2}{*}{$\begin{array}{c}\text { Bulk Fluid } \\
\text { Temperatu } \\
\text { re }^{\circ} \mathrm{C}\end{array}$} & \multicolumn{8}{|c|}{ Inner wall Temperature ${ }^{\circ} \mathrm{C}$} \\
\hline & & & & & & Expt. & CFD & Mokry & Jackson & Zhu & Mcadams & $\begin{array}{l}\text { Watts } \\
\text { \&chou }\end{array}$ & Dittus \\
\hline 1 & 0.05 & 504 & 141 & 0.28 & 350.9 & 365.6 & 364.8 & 369.2 & 367.1 & 368.2 & 366.7 & 368.3 & 367.6 \\
\hline 2 & 0.11 & 504 & 141 & 0.28 & 351.8 & 367.9 & 366.5 & 369.9 & 367.9 & 368.9 & 367.5 & 368.9 & 368.4 \\
\hline 3 & 0.15 & 504 & 141 & 0.28 & 352.7 & 369.2 & 367.5 & 370.6 & 368.7 & 369.6 & 368.4 & 369.6 & 369.2 \\
\hline 4 & 0.21 & 504 & 141 & 0.28 & 354.0 & 370.1 & 368.5 & 371.6 & 369.8 & 370.6 & 369.6 & 370.6 & 370.5 \\
\hline 5 & 0.30 & 504 & 141 & 0.28 & 355.8 & 371.4 & 369.9 & 372.9 & 371.3 & 372.0 & 371.2 & 372.0 & 372.1 \\
\hline 6 & 0.52 & 504 & 141 & 0.28 & 358.0 & 375.4 & 372.3 & 374.5 & 373.2 & 373.6 & 373.2 & 373.5 & 374.1 \\
\hline 7 & 0.68 & 504 & 141 & 0.28 & 360.7 & 376.3 & 374.2 & 376.2 & 375.3 & 375.4 & 375.6 & 375.3 & 376.5 \\
\hline 8 & 0.02 & 498 & 190 & 0.38 & 351.7 & 365.8 & 367.5 & 375.6 & 373.2 & 374.2 & 373.1 & 373.6 & 374.3 \\
\hline 9 & 0.07 & 498 & 190 & 0.38 & 352.5 & 370.8 & 371.3 & 376.1 & 373.9 & 374.7 & 373.8 & 374.1 & 375.0 \\
\hline 10 & 0.23 & 498 & 190 & 0.38 & 355.8 & 376.6 & 375.1 & 377.9 & 376.4 & 376.5 & 376.8 & 376.1 & 378.0 \\
\hline 11 & 0.27 & 498 & 190 & 0.38 & 355.8 & 376.6 & 375.9 & 377.9 & 376.3 & 376.5 & 376.8 & 376.1 & 377.9 \\
\hline 12 & 0.30 & 498 & 190 & 0.38 & 356.6 & 377.4 & 376.3 & 378.3 & 376.9 & 376.9 & 377.5 & 376.6 & 378.7 \\
\hline 13 & 2.45 & 498 & 190 & 0.38 & 384.5 & 394.5 & 391.5 & 403.3 & 399.8 & 402.9 & 395.5 & 404.3 & 396.1 \\
\hline 14 & 2.63 & 498 & 190 & 0.38 & 383.6 & 395.3 & 391.6 & 400.5 & 397.2 & 400.3 & 393.1 & 401.6 & 393.6 \\
\hline 15 & 2.94 & 498 & 190 & 0.38 & 385.2 & 396.9 & 391.8 & 405.4 & 401.8 & 404.8 & 397.4 & 406.3 & 398.0 \\
\hline 16 & 1.56 & 1503 & 590 & 0.39 & 375.4 & 391.8 & 387.0 & 393.0 & 394.7 & 387.9 & 389.8 & 395.7 & 396.4 \\
\hline 17 & 1.61 & 1503 & 590 & 0.39 & 376.2 & 391.8 & 387.0 & 393.5 & 395.0 & 388.8 & 389.4 & 396.2 & 396.1 \\
\hline 18 & 1.79 & 1503 & 590 & 0.39 & 377.9 & 391.8 & 387.0 & 394.4 & 395.1 & 390.7 & 388.8 & 397.1 & 394.9 \\
\hline 19 & 1.84 & 1503 & 590 & 0.39 & 377.9 & 391.8 & 387.0 & 394.4 & 395.1 & 390.7 & 388.8 & 397.1 & 394.9 \\
\hline 20 & 2.06 & 1503 & 590 & 0.39 & 378.7 & 395.9 & 387.2 & 394.7 & 394.9 & 391.7 & 389.5 & 397.4 & 393.9 \\
\hline 21 & 2.22 & 1503 & 590 & 0.39 & 379.5 & 396.7 & 387.6 & 395.0 & 394.5 & 392.7 & 389.9 & 397.6 & 392.6 \\
\hline 22 & 1.22 & 1002 & 484 & 0.48 & 375.6 & 401.9 & 387.6 & 403.1 & 399.2 & 394.2 & 397.8 & 402.0 & 399.1 \\
\hline 23 & 1.40 & 1002 & 484 & 0.48 & 377.6 & 401.0 & 388.4 & 403.5 & 399.2 & 396.5 & 396.4 & 402.8 & 397.5 \\
\hline 24 & 1.43 & 1002 & 484 & 0.48 & 377.6 & 401.0 & 388.7 & 403.5 & 399.2 & 396.5 & 396.4 & 402.8 & 397.5 \\
\hline 25 & 1.57 & 1002 & 484 & 0.48 & 378.6 & 402.0 & 390.4 & 403.5 & 398.7 & 397.7 & 395.1 & 402.9 & 396.0 \\
\hline 26 & 1.75 & 1002 & 484 & 0.48 & 379.6 & 402.0 & 392.4 & 403.1 & 397.8 & 399.0 & 393.3 & 402.9 & 394.0 \\
\hline 27 & 1.78 & 1002 & 484 & 0.48 & 381.6 & 402.0 & 392.7 & 404.5 & 397.7 & 403.6 & 391.0 & 404.9 & 391.6 \\
\hline 28 & 1.94 & 1002 & 484 & 0.48 & 380.7 & 403.1 & 393.7 & 402.9 & 396.8 & 400.8 & 391.2 & 403.0 & 391.8 \\
\hline 29 & 2.08 & 1002 & 484 & 0.48 & 381.7 & 404.1 & 394.5 & 404.7 & 397.9 & 403.9 & 391.2 & 405.2 & 391.7 \\
\hline 30 & 2.20 & 1002 & 484 & 0.48 & 382.7 & 405.1 & 395.2 & 409.1 & 401.8 & 408.2 & 394.0 & 409.9 & 394.6 \\
\hline
\end{tabular}


Table 5 Typical comparison of wall temperatures predicted by CFD and selected correlations with experimental data Mokry et al. (2010) \& Mokry et al. (2011) (for heat transfer deterioration Zone).

\begin{tabular}{|c|c|c|c|c|c|c|c|c|c|c|c|c|}
\hline \multirow[b]{2}{*}{ Sl.No } & \multirow[b]{2}{*}{$\begin{array}{c}\text { Length } \\
\text { (m) }\end{array}$} & \multirow[b]{2}{*}{$\begin{array}{l}\text { Mass Flux } \\
(G) \mathrm{kg} / \mathrm{m}^{2} \mathrm{~s}\end{array}$} & \multirow[b]{2}{*}{$\begin{array}{l}\text { Heat Flux } \\
\text { (q) } k W / m^{2}\end{array}$} & \multirow[b]{2}{*}{$\begin{array}{c}\text { Bulk Fluid } \\
\text { Temperature } \\
{ }^{\circ} \mathrm{C}\end{array}$} & \multicolumn{8}{|c|}{ Inner wall Temperature ${ }^{\circ} \mathrm{C}$} \\
\hline & & & & & Expt. & CFD & Zhu & Ornatsky & Jackson & Bishop & Mokry & $\begin{array}{l}\text { Watts } \\
\text { \&chou }\end{array}$ \\
\hline 1 & 0.11 & 499 & 289 & 353.8 & 385.3 & 383.1 & 383.5 & 403.4 & 382.9 & 384.8 & 387.8 & 377.7 \\
\hline 2 & 0.24 & 499 & 289 & 357.6 & 392.2 & 387.4 & 380.8 & 404.8 & 386.0 & 387.8 & 392.5 & 383.7 \\
\hline 3 & 0.37 & 499 & 289 & 360.7 & 392.2 & 403.9 & 382.6 & 405.6 & 388.9 & 390.2 & 396.5 & 382.4 \\
\hline 4 & 0.46 & 499 & 289 & 363.2 & 395.4 & 404.3 & 384.8 & 405.9 & 391.2 & 392.0 & 399.7 & 383.6 \\
\hline 5 & 0.60 & 499 & 289 & 366.4 & 399.2 & 404.8 & 388.6 & 405.7 & 394.1 & 394.1 & 403.5 & 386.4 \\
\hline 6 & 0.64 & 499 & 289 & 368.9 & 402.3 & 405.0 & 391.7 & 405.1 & 396.4 & 395.5 & 406.4 & 389.6 \\
\hline 7 & 1.13 & 499 & 334 & 378.5 & 425.0 & 418.1 & 412.9 & 411.8 & 406.2 & 407.5 & 428.9 & 416.9 \\
\hline 8 & 1.23 & 499 & 334 & 380.0 & 423.5 & 419.5 & 414.6 & 407.1 & 403.8 & 407.2 & 425.0 & 417.6 \\
\hline 9 & 1.31 & 499 & 334 & 380.0 & 425.0 & 420.9 & 414.6 & 407.1 & 403.8 & 407.2 & 425.0 & 417.6 \\
\hline 10 & 1.34 & 499 & 334 & 381.5 & 426.5 & 421.3 & 418.3 & 403.7 & 403.0 & 409.1 & 423.0 & 416.3 \\
\hline 11 & 1.50 & 499 & 334 & 380.0 & 426.5 & 423.4 & 414.6 & 407.1 & 403.8 & 407.2 & 425.0 & 417.6 \\
\hline 12 & 1.53 & 499 & 334 & 380.0 & 426.5 & 423.9 & 414.6 & 407.1 & 403.8 & 407.2 & 425.0 & 417.6 \\
\hline 13 & 2.43 & 994 & 686 & 387.5 & 445.1 & 436.7 & 450.4 & 436.1 & 439.2 & 444.5 & 462.7 & 457.7 \\
\hline 14 & 2.58 & 994 & 686 & 386.2 & 447.8 & 440.6 & 446.3 & 430.9 & 433.7 & 439.4 & 457.4 & 451.9 \\
\hline 15 & 2.65 & 994 & 686 & 388.8 & 447.8 & 442.3 & 454.1 & 440.9 & 444.2 & 449.1 & 467.5 & 462.9 \\
\hline 16 & 2.74 & 994 & 686 & 388.8 & 449.1 & 445.1 & 454.1 & 440.9 & 444.2 & 449.1 & 467.5 & 462.9 \\
\hline 17 & 2.82 & 994 & 686 & 388.8 & 450.4 & 447.7 & 454.1 & 440.9 & 444.2 & 449.1 & 467.5 & 462.9 \\
\hline 18 & 3.11 & 994 & 686 & 391.5 & 457.1 & 458.7 & 460.9 & 449.7 & 453.0 & 457.3 & 476.0 & 472.2 \\
\hline 19 & 1.71 & 206 & 166 & 386.3 & 460.6 & 436.8 & 447.5 & 422.9 & 427.5 & 440.9 & 459.8 & 442.2 \\
\hline 20 & 1.80 & 206 & 166 & 387.9 & 460.6 & 438.1 & 452.1 & 428.1 & 433.0 & 446.7 & 465.8 & 454.6 \\
\hline 21 & 1.88 & 206 & 166 & 389.4 & 459.1 & 440.8 & 456.3 & 432.9 & 438.1 & 451.8 & 471.2 & 458.3 \\
\hline 22 & 2.06 & 206 & 166 & 388.0 & 459.2 & 445.1 & 452.4 & 428.4 & 433.4 & 447.0 & 466.2 & 454.8 \\
\hline 23 & 2.13 & 206 & 166 & 389.5 & 459.2 & 448.5 & 456.5 & 433.2 & 438.3 & 452.1 & 471.5 & 458.6 \\
\hline 24 & 2.17 & 206 & 166 & 389.6 & 457.7 & 450.1 & 456.6 & 433.2 & 438.4 & 452.2 & 471.6 & 458.6 \\
\hline 25 & 3.46 & 1000 & 826 & 408.8 & 514.7 & 547.2 & 517.7 & 516.9 & 516.9 & 523.4 & 552.4 & 545.3 \\
\hline 26 & 3.66 & 1000 & 826 & 417.6 & 525.7 & 561.8 & 532.7 & 536.7 & 534.8 & 540.8 & 569.4 & 563.8 \\
\hline 27 & 3.80 & 1000 & 826 & 426.5 & 539.0 & 572.2 & 546.5 & 554.5 & 550.6 & 556.4 & 584.7 & 580.3 \\
\hline 28 & 3.85 & 1000 & 826 & 426.5 & 543.4 & 576.2 & 546.5 & 554.5 & 550.6 & 556.4 & 584.7 & 580.3 \\
\hline 29 & 3.91 & 1000 & 826 & 430.9 & 550.0 & 580.2 & 553.1 & 562.7 & 558.0 & 563.7 & 591.9 & 587.9 \\
\hline 30 & 3.94 & 1000 & 826 & 430.9 & 554.4 & 583.4 & 553.1 & 562.7 & 558.0 & 563.7 & 591.9 & 587.9 \\
\hline
\end{tabular}

